\title{
Teorias De Educação Matemática: \\ Contribuições Na Formação Do Futuro Pesquisador
}

\author{
Theories Of Mathematical Education: \\ Contributions In The Formation Of The Future Researcher
}

\author{
Rita Lobo Freitas * \\ Universidade do Estado da Bahia - (UNEB) \\ Sonia Barbosa Camargo Igliori** \\ Pontifícia Universidade Católica de São Paulo - (PUC-SP)
}

\begin{abstract}
Resumo
Este artigo tem como objetivo apresentar um estudo sobre elementos teóricos de diferentes autores que influenciam e atuam diretamente nas discussões sobre problemas no ensino e aprendizagem da matemática, durante aulas de teorias de educação matemática em um programa de doutorado, realizado em uma universidade brasileira. $\mathrm{O}$ principal objetivo aqui foi identificar quais contribuições este estudo construiu para a formação de um potencial pesquisador em educação matemática. É organizado em categorias, de acordo com teorias e trabalhos correlatos estudados, tomando como perspectiva os aspectos históricos, filosóficos, epistemológicos e cognitivos da educação matemática. Após uma cuidadosa análise sobre os temas estudados, as construções escritas e uma produção de seminários dos alunos, foi possível deduzir que o trabalho realizado durante essas aulas poderia auxiliar na aquisição de conhecimentos sobre uma área em constituição, seus conflitos e alguns de seus conceitos teóricos.
\end{abstract}

Palavras-chave: Educação Matemática; Teorias; Epistemologia

\begin{abstract}
This article aims to show a study about theoretical elements from different authors that influence and act directly on discussions about problems at teaching and learning Mathematics, during classes of theories of mathematics education inside a doctorate's program, done at a brazilian university. The main objective here was to identify which contributions this study built for the formation of a potential mathematics education researcher. It is organized in categories, in according to theories and corelated works studied, taking as a perspective the historical, philosophical, epistemological and cognitive aspects of mathematics education. After a careful analysis about the studied themes, the constructions written and a production of seminaries from the students, it was possible to deduce that the work made while those classes could help the acquisition of knowledge about an area in constitution, its conflicts and some of its theoretical concepts.
\end{abstract}

Keywords: Mathematics Education; Theories; Epistemology

\footnotetext{
* Mestra em Educação Matemática Pontifícia Univrsidade Católica de São Paulo (PUC-SP). Professora assistente da Universidade do Estado da Bahia (UNEB),Salvador, Bahia, Brasil.: realizou estágio de doutorado sanduiche na França em 2017 com apoio da CAPES. E-mail:ritalobof@gmail.com.

** Doutora em Matemática Pontifícia Universidade Católica de São Paulo (PUC-SP). Professora titular do Departamento de Matemática da PUC-SP, São Paulo, e Professora do PEPG em Educação Matemática da PUCSão Paulo Brasil, com pós doutorados realizados na França em 1995 e 2018 com apoio CAPES. E-maill: sigliori@pucsp.br
} 


\section{Introdução}

Neste artigo apresentamos uma síntese dos estudos teóricos realizados em um curso de pós-graduação brasileiro, em nível de doutorado, no âmbito de uma disciplina denominada Teorias de Educação Matemática (TEM). A nossa posição neste trabalho é dar vozes aos autores e/ou suas concepções teóricas estudados nessa disciplina e desenvolver um posicionamento crítico sobre a importância desse estudo para a formação de futuros pesquisadores em Educação Matemática.

Em linhas gerais a disciplina TEM, abordou tópicos de diferentes trabalhos de pesquisadores, teóricos estudados na Educação Matemática (EM), tanto no âmbito internacional como nacional. Os temas abordados em TEM tiveram um encadeamento concomitante, ou seja, a cada encontro discutíamos e realizávamos a leitura de diferentes trabalhos, sejam artigos ou trechos de livros. Além disso, havia os momentos dos seminários, em que participante apresentava um artigo que poderia ter relevância para a sua pesquisa de doutorado. Esse formato permitiu, pouco a pouco construir uma visão geral de cada tema.

Sobre os seminários, cada participante pode escolher, de forma livre, o artigo que julgou relevante para sua pesquisa de doutorado, sendo abordado os seguintes trabalhos: "enquanto isso na sociedade de consumo líquido-moderna: a produção de significados e a tomada de decisão de indivíduos consumidores"; "la tarea intelectual en matemáticas afecto, meta-afecto y los sistemas de creencias"; "reflexões sobre a história da matemática na formação de professores"; "o lugar das matemáticas na licenciatura em matemática: que matemáticas e que práticas formativas?" "contribuições da didática da matemática para compreensão dos impactos do vazio didático na prática dos professores de matemática que evoca as inter-relações entre os domínios numérico-algébrico e geométrico".

Além dos seminários, construímos várias produções escritas por meio de sínteses sobre os textos estudados. Para cada encontro tínhamos um planejamento prévio a ser executado e o mesmo era revisado a cada semana, nesse trabalho traremos as contribuições teóricas do que foi realizado na disciplina TEM, dando voz aos diferentes autores estudados.

\section{Educação Matemática Uma Área Em Constituição: Breve Histórico}

Antes de iniciar uma discussão sobre teorias de Educação Matemática, julgamos necessário situar a constituição desta suposta área de conhecimento, tendo como fonte o artigo: “A Educação Matemática: breve histórico, ações implementadas e questões sobre sua 
disciplinarização" os autores trazem particularmente o movimento pelo qual a EM passou em sua trajetória para se constituir ou não uma disciplina. Esse tópico foi muito importante na disciplina TEM, pois nos possibilitou conhecer um pouco mais sobre a história da EM no Brasil, sobre a ótica de seus construtores.

No referido artigo, os autores Igliori, Miguel, Ganica e D'Ambrosio (2004) trataram conjuntamente sobre a configuração da EM como área de pesquisa, num panorama histórico, de como foram implementados esforços para a consolidação da EM como área de conhecimento autônoma, uma disciplina.

Inicialmente os autores, na voz de D’Ambrosio, apresentam notas históricas sobre a emergência e a organização da pesquisa em Educação Matemática, nos Estados Unidos e no Brasil, tendo como pano de fundo a EM como disciplina. Nesse sentido inicia com um levantamento histórico de obras que retratavam as preocupações com o ensino de Matemática desde a antiguidade e mais recentemente com a Educação Matemática. A seguir sinalizaremos os pontos mais relevantes desse histórico retratado por D'Ambrosio.

Em 1901 com o cientista John Perry é expressa a preocupação com um método de ensino que possibilitasse atender tanto aqueles jovens que gostavam de raciocínio abstrato como aqueles que não gostavam, foi o início de uma crise e conflitos de opiniões entre matemáticos e educadores para uma reforma educacional.

D’Ambrosio destaca que a mais importante contribuição, para o estabelecimento da EM como uma disciplina foi a do matemático alemão Felix Klein que publicou, em 1908, o livro Matemática elementar de um ponto de vista avançado. Klein centrou sua discussão em uma escola que se atentasse às bases psicológicas mais do que as sistemáticas, o professor deveria, portanto, levar em conta o processo psíquico do aluno. Klein liderou a fundação da Comissão Internacional de Instrução Matemática, conhecida pelas siglas IMUK/ICMI, durante o Congresso Internacional de Matemáticos, em 1908, evento que tem o marco da consolidação da EM como uma subárea da Matemática e da Educação, de natureza interdisciplinar. (MIGUEL et al, 2004)

De acordo com o relato de D'Ambrosio (IGLIORI et al, 2004), em meio a muitas reflexões de natureza filosófica, no século XX, uma intensa pesquisa em Educação começa a se desenvolver, a Educação ganha novas características e é marcada pelos movimentos sociais, pelos novos conhecimentos. Em 1916 é fundada a American Educational Research Association (AERA), apesar de já existirem outros grupos como American Mathematical Society (AMS) e a Mathematical Association of America (MAA), fundadas respectivamente em 1894 e 1915, 
que tinham algumas preocupações com o ensino de Matemática, preocupações e propostas dos professores de Matemática (sobretudo daqueles envolvidos com a educação pré-universitária) encontravam pouca repercussão e espaço de reflexão dos seus interesses, o que levou a fundação da National Council of Teachers of Mathematics (NCTM). (IGLIORI et al, 2004)

Um marco para efervescência da EM em todo mundo, foi o pós guerra, florescendo o desenvolvimento curricular. As bases teóricas de aprendizagem são defendidas por psicólogos como Jean Piaget, Robert M. Gagné e Jerome Bruner, B. F. Skinner. Nos Estados Unidos muitos projetos tiveram repercussão internacional, em 1969 realizou-se em Lyon, França, o Primeiro Congresso Internacional de EM (ICME). A cada quatro anos, reúne-se um ICME, com a presença de pesquisadores em EM de todo o mundo e organizado sob a responsabilidade da Internacional Commission of Mathematics Instruction (ICMI), uma das comissões especializadas da International Mathematics Union (IMU). (IGLIORI et al, 2004)

A partir deste breve histórico os autores fazem um paralelo e consideram que a Associação Nacional de Pós-Graduação e Pesquisa em Educação (ANPEd) e a Sociedade Brasileira de EM(SBEM) representam, no Brasil, objetivos respectivamente semelhantes aos da AERA e do NCTM, enquanto o GT 19 é o equivalente ao Special Interest Group (SIG) em Research in Mathematics Education (RME) -SIG/RME, e o Seminário Internacional de Pesquisa em EM(SIPEM) o correspondente ao Research Advisory Committee (RAC) do NCTM.

Nesse histórico os autores retratam por meio da fala de Igliori, o percurso e a importância da criação de um grupo de trabalho na ANPEd, que além da identidade de temáticas de pesquisa, indicava ser essa Associação um espaço bem adequado para a organização dos pesquisadores em Educação Matemática. Segundo Igliori "a criação de um grupo de trabalho numa associação nacional do porte da ANPEd, que congregasse pesquisa de uma determinada área de saber, pressupõe, antes de tudo, reconhecimento da área pela academia”. (IGLIORI et al, 2004, p. 73)

No final da década de 1980 e início de 1990 é sinalizado por Igliori como período em que a divulgação das pesquisas em EM se restringia às revistas Bolema e Zétetike e aos trabalhos acadêmicos com fins de titulação. Além da consolidação dos programas de pósgraduação específicos em EM (Unesp-Rio Claro e PUC-SP) a Sociedade Brasileira de EM (SBEM) em seus encontros abrigava muito mais experiências sobre o ensino de Matemática do que, pesquisas acadêmicas sobre Educação Matemática. Paralelo a tudo isso o número de doutores, com títulos obtidos fora do Brasil se ampliava. 
É neste cenário que ocorrem diversos debates sobre a existência ou não de um GT de Educação Matemática, relatados nos depoimentos dos autores, pesquisadores envolvidos no processo. Após a criação prévia do Grupo de Estudos (GE) em Educação Matemática, o qual trabalhou por dois anos sob a coordenação de Sonia Igliori, em 1999 institui-se o GT 19 de EM da ANPEd.

A principal questão de debate, mesmo nos dias atuais, em nosso ponto de vista, é o projeto de disciplinarização da Educação Matemática, retratada no depoimento de Miguel. O autor em sua fala situa o problema do lócus da EM frente às demais áreas de conhecimento, constituídas e institucionalizadas, como algo que vinha sendo discutido pela comunidade internacional e brasileira em diferentes espaços nos quais a EM era tematizada (universidades, escolas, associações profissionais, entre outros).

De acordo com Miguel, embora a EM seja uma prática social interdisciplinar e, portanto, estaria aberta ao diálogo com as demais práticas sociais, o diálogo com os educadores no interior dos institutos de Matemática é bem diferente do diálogo com os matemáticos nos institutos de Educação. Seria mais diferente ainda, se fosse possível vivenciar esses diálogos num instituto ou departamento de Educação Matemática, o que seria possível apenas se a EM já tivesse se constituído como um campo disciplinar autônomo. Isso não acontece pois ela não está topologicamente, institucionalmente e tão pouco juridicamente estabelecida como campo disciplinar autônomo. (IGLIORI et al, 2004)

O autor sinaliza que apesar da EM ter construído congressos, suas sociedades científicas, grupos de pesquisas e revistas especializadas, ainda não havia um consenso o interior da área, apesar de existirem ações concretas em diferentes espaços para viabilizar um projeto de disciplinarização. Miguel defende uma discussão aberta e democrática no interior da comunidade e traz como contribuição a sua visão de que a EM se caracteriza como uma prática social, o que segundo ele vai além do debate da existência ou não de um GT. (IGLIORI et al, 2004)

Nesse sentido (IGLIORI et al, 2004) define prática social como um conjunto composto pelos seguintes elementos: uma comunidade; um conjunto de ações realizadas pelas pessoas dessa comunidade em um espaço e tempo determinados; um conjunto de finalidades orientadoras de tais ações e um conjunto de conhecimentos produzidos por tal comunidade.

A noção de prática social é concebida, de acordo com Miguel, como atividades sociais realizadas por um conjunto de indivíduos que produzem conhecimentos, e não apenas ao conjunto de conhecimentos produzidos por esses indivíduos em suas atividades. Além disso, 
existe entre as práticas sociais a produção, interação e apropriação dos conhecimentos desenvolvidos por diferentes práticas sociais e entre elas, contemporâneas ou não, que convivem ou não no mesmo espaço geográfico.

Sobre a apalavra disciplinarização oriunda do campo semântico da palavra disciplina, o autor procura dar um sentido bem mais amplo do que essa última, define como um campo autônomo de investigação e de formação profissional institucionalmente legitimado, topologicamente diferenciado no interior do espaço acadêmico e juridicamente estabelecido como campo profissional autônomo. Nesse sentido o projeto de disciplinarização se refere ao processo histórico-social de transformação de uma prática social em uma disciplina acadêmica concebida do modo como acima identificado. (MIGUEL et al, 2004)

A reflexão empreendida no GT de EM pelo autor se refere a esse projeto de disciplinarização da prática social em Educação Matemática. Esse processo só é explicável com base no potencial de sintonização dos propósitos e dos conhecimentos produzidos no interior dessa prática com a viabilização dos propósitos subjacentes ao projeto político, social, econômico e cultural de grupos sociais com capacidade concreta de influir sobre a gestão político-administrativa da vida de uma nação. (IGLIORI et al, 2004)

De acordo com Miguel a maior resistência ao projeto de disciplinarização estaria situado no interior do próprio meio acadêmico, ou, mais particularmente, entre os matemáticos profissionais e os profissionais da educação, no entanto é natural dar continuidade à esta reflexão introduzindo os campos disciplinares da matemática e da educação como principais interlocutores. (IGLIORI et al, 2004)

Essa interlocução será mais histórica do que epistemológica pois os processos de disciplinarização não poderiam ser explicados através de uma "lógica" predeterminada e previsível. As pesquisas da história das ciências mostram que não foi dessa forma que ocorreram os diferentes os processos de disciplinarização. É preciso, portanto, buscar apoio em estudos de caso concretos de disciplinarização suficientemente específicos e pertinentes à nossa reflexão particular. (IGLIORI et al, 2004)

Refletimos que este tópico discutido em mais de um encontro da disciplina TEM, permitiu ter uma visão ampla, ainda que parcial, da constituição e consolidação da área da Educação Matemática. Nesse sentido os demais itens desse artigo se articulam nessa discussão da consolidação da área de EM e de suas possíveis teorias. 


\section{Teorias E Filosofias Da Educação Matemática}

No estudo desse tema realizamos um pequeno recorte do livro "Theories of Mathematics Education", Sriraman e English (2010), apresentando as principais contribuições dos autores estudados no livro. Inicialmente no prefácio escrito por Kilpatrick, fica evidenciado a importância do debate acerca da existência de uma teoria da Educação Matemática.

Além do prefácio da obra Sriraman e English (2010) é importante relatar os aspectos relevantes apresentados acerca das teorias e filosofias da Educação Matemática, nos trechos desse livro. De acordo com os autores qualquer teoria do pensamento, do ensino e da aprendizagem, apoia-se na filosofia do conhecimento. A EM se apoia na Educação e na Matemática e em inúmeras outras disciplinas, que interagem com esses dois domínios, isso compõe uma complexidade do desenvolvimento de teorias que definem a Educação Matemática. A questão posta pelos autores é se teorias de EM são construtíveis, assim recorrem a Lincoln e Guba (1994) quando afirmam que qualquer disciplina precisa definir para si três perguntas: qual a realidade ou qual é a natureza do mundo que nos rodeia? como conhecer o mundo que nos rodeia e como podemos estar certos da verdade de que conhecemos?

A primeira pergunta está relacionada à questão geral e ontológica da definição de objetos (real, concreto, abstrato, existente ou não existente). A segunda questão é metodológica, sobre as possibilidades das várias disciplinas desenvolverem paradigmas metodológicos e a terceira se relaciona com a questão epistemológica. Esses critérios são rotulados por alguns teóricos educacionais como blocos de construção de um paradigma, enquanto outros argumentam que podem constituir os fundamentos de uma filosofia para Educação Matemática. (SRIRAMAN e ENGLISH, 2010)

Em uma segunda etapa os autores relatam a influência filosófica de alguns teóricos para a Educação Matemática. Inicialmente Jean Piaget, na sua visão de cognição, mesmo que interpretado de formas diferentes por visões teóricas distintas, como o construtivismo radical e o construtivismo social. Destacam a relevância do livro de Imre Lakatos, Provas e Refutações, como uma influência filosófica para a EM sobre as teorias de aprendizagem e desenvolvimento da Matemática. (SRIRAMAN e ENGLISH, 2010)

Essa obra é considerada preferida pelos construtivistas sociais por conta da concepção da certeza matemática, como estando sujeita a revisão no decurso do tempo, a fim de levar adiante o ponto de vista falível sobre a Matemática. Esta posição se contrasta com o ponto de vista platônico, que vê a Matemática como um corpo unificado de conhecimentos com uma 
certeza ontológica e uma infalível estrutura subjacente. (SRIRAMAN e ENGLISH, 2010)

Sobre o trabalho de Paul Ernest, os autores descrevem como uma tentativa de desenvolver uma filosofia independente, ou seja, uma filosofia social construtivista da (educação) matemática. A palavra educação aparece entre parênteses porque segundo os aut Ernest não faz qualquer argumento explícito associado à pedagogia.

Sriraman e English (2010) destacam o surgimento do construtivismo social, como Filosofia da Educação Matemática, o interesse pela semiótica matemática além do enfoque sobre a natureza cultural da Matemática. Expressam ainda, que a Filosofia associada a EM deveria incluir um amplo espectro de disciplinas, como sinalizou Hersh (2006), que uma filosofia deveria incluir vozes dos cientistas cognitivos, linguistas, sociólogos, antropólogos, matemáticos e filósofos.

Os autores por fim questionam se a obra de Lakatos está diretamente relacionada ao ensino e aprendizagem de Matemática, apesar de afirmarem que provas e refutações pode servir de base para uma filosofia matemática, como uma filosofia social construtivista da Matemática, que, por sua vez, pode ser utilizada como base para desenvolver uma teoria de aprendizagem tal como construtivismo. (SRIRAMAN e ENGLISH, 2010)

O principal argumento dos autores da relevância de Lakatos para a EM é do ponto de vista de fazer com que a pesquisa e seus praticantes, nesse caso ambos, se embasem em uma filosofia subjacente, uma teoria de aprendizagem associada.

De acordo com Sriraman e English (2010) é natural e necessária a diversidade do número de teorias utilizadas no ensino de Matemática, a partir de diferentes domínios do conhecimento: cognitivo, sociológico, antropológico e das neurociências, dada a complexidade dos processos de ensino e aprendizagem de situações matemáticas, além do aumento significativo na complexidade conceitual da disciplina. Essa complexidade é ainda maior por questões ontológicas e epistemológicas, que confrontam tanto a EM como a Educação em geral. Nesse sentido o desenvolvimento de modelos teórico universais tem sido problemático para a EM.

Os autores também relatam a crescente preocupação de alguns pesquisadores, e até um certo ceticismo, de que a pesquisa guiada por teorias pode ser relevante e melhorar o ensino e a aprendizagem de Matemática em sala de aula. Demonstrar isso tem sido um grande desafio para a EM. (SRIRAMAN e ENGLISH, 2010)

Esse texto proporciona uma reflexão sobre as influências filosóficas na Educação Matemática. Além disso, possibilita uma melhor compreensão acerca da existência ou não de 
teorias em Educação Matemática, e também de visualizar o quanto a nossa área "bebe" de fundamentos teóricos e filosóficos de outras áreas, isso também lhe fornece um caráter interdisciplinar.

No entanto, apesar da relevância do estudo realizado, se faz necessário buscar uma continuidade afim de aprofundar mais os conhecimentos sobre as filosofias da EM e sobre o papel da teoria para a Educação Matemática. Nesse sentido o tópico apresentado a seguir, sobre as fontes do conhecimento e da ignorância, amplia um pouco a nossa visão sobre os aspectos filosóficos subjacentes às teorias do conhecimento.

\section{As Fontes do Conhecimento e da Ignorância: Conjecturas E Refutações}

Este tópico se refere ao estudo realizado sobre uma parte do trabalho de Karl Popper, que se situa em trechos do livro: "Conjecturas e Refutações" do qual extraímos as ideias principais do autor, e abordamos o ponto de vista de Popper no âmbito da epistemologia do conhecimento.

Como epistemólogo o autor demonstra o seu interesse pelos problemas da Epistemologia e se questiona se não estará sujeito à influência, mesmo que inconscientemente, pelas esperanças e convicções políticas. Se considera um misto de empirista e racionalista e também um liberal, por esta razão acredita que o mais importante para um liberal é submeter as várias teorias do liberalismo a uma rigorosa análise crítica. Defende que na procura pela verdade, o melhor é começar por criticar as crenças que mais se preza, mesmo que isso pareça um plano perverso, mas não parecerá para aqueles que querem descobrir a verdade e não têm receio dela.

Inicialmente o autor, levanta um debate sobre as fontes do conhecimento e da ignorância, assim espera atrair a atenção sobre algumas doutrinas filosóficas, cita a doutrina em que a verdade é manifesta e dá um especial destaque para a teoria conspiratória da ignorância, esta última segundo o autor interpreta a ignorância como uma obra de um poder sinistro, fonte de influências impuras e maléficas que pervertem as mentes no sentido de incitar um hábito à resistência ao conhecimento (POPPER, 2006).

Num primeiro momento, procura reexaminar e resolver o problema do conflito entre a visão da escola britânica e da escola continental de filosofia, no que diz respeito ao empirismo clássico (Bacon, Locke, Berkeley, Hume e Mill) e do racionalismo clássico (Descartes, Espinosa e Leibniz). A escola britânica defendia como fonte última do conhecimento a 
observação e a escola continental defendia que era a intuição intelectual das ideias claras e distintas. Popper (2006) afirma que as diferenças que separam essas duas escolas são ultrapassadas pelas suas semelhanças, mas que ambas estão enganadas, mesmo ele próprio se considera um pouco racionalista e empirista.

Em um segundo momento o autor situa a discussão como um problema pertencente à teoria do Conhecimento ou da Epistemologia, conhecida por sua abstração e irrelevância para a Filosofia pura. Cita as perspectivas adotadas por Hume, Kant, Bertand Russel, a visão de Kant sobre a epistemologia pode ser traduzida pela frase: "o que posso conhecer", para Russel não existe uma verdade objetiva, e o pragmatismo epistemológico, estão estreitamente associados a ideias autoritárias e totalitárias.

De acordo com Popper (2006) as ideias de Russel são contestadas, e alguns filósofos desenvolveram uma doutrina da impotência essencial e da irrelevância prática de toda verdadeira Filosofia, e nessa medida, da Epistemologia. O autor afirma que a crença na possibilidade de um estado de direito, de justiça e de liberdade dificilmente pode sobreviver à admissão de uma epistemologia que defende a inexistência de fatos objetivos.

O Renascimento, segundo Popper (2006) foi um movimento inspirado por um certo otimismo epistemológico, uma visão extremamente otimista do poder humano em discernir a verdade e adquirir conhecimento. No centro dessa perspectiva reside a doutrina de que a verdade é manifesta, ou seja, a verdade pode estar velada, mas pode ser desvelada por nós ou por si própria. Ainda que não seja fácil, uma vez que a verdade surgir diante de nossos olhos teremos o poder de distinguir o que é falso e, portanto, saber que ela é a verdade.

De forma geral a doutrina de que a verdade é manifesta torna necessário explicar a falsidade, o conhecimento, a posse da verdade não precisa de explicação. De acordo com o autor nossas mentes abrigam preconceitos inculcados pela educação e pela tradição, ou por outras influências. Além disso, a ignorância pode ser obra de poderes que conspiram para nos manter ignorantes, para cegar os nossos olhos enchendo-os de falsidades de forma a não poderem ver a verdade manifesta. A teoria conspiratória da ignorância, é conhecida pela forma marxista como a conspiração da imprensa capitalista, que perverte e suprime a verdade, enchendo a mente dos trabalhadores de falsas ideologias, entre essas ideologias destaca-se as doutrinas de religião.

De acordo com Popper (2006) foi a partir da epistemologia otimista que inspirou o nascimento da ciência e tecnologia modernas com Bacon e Descartes. De acordo com os quais o homem para distinguir a verdade do erro, pode utilizar a percepção dos seus sentidos, para 
aplicar a cuidadosa observação da natureza ou pelo seu poder de intuição intelectual. Nesse sentido reside o racionalismo de Descartes. A fórmula que explica a conexão entre o otimismo epistemológico e as ideias do liberalismo é que, o homem pode conhecer: por isso pode ser livre.

Contrapondo-se a estas ideias vem a descrença no poder do homem de discernir a verdade (o poder da razão humana) essa, quase invariavelmente ligada à desconfiança no próprio homem. Dessa forma surge historicamente, um pessimismo epistemológico associado a uma doutrina de depravação humana, conduzindo à exigência de implantação de uma autoridade que salve o homem da sua perversidade e loucura (POPPER, 2006).

Segundo o autor, o contraste entre o pessimismo e o otimismo epistemológico é fundamentalmente análogo ao existente entre o tradicionalismo (convicção de que na ausência de uma verdade objetiva e discernível, confronta-se com a escolha entre a autoridade da tradição e o caos) e o racionalismo epistemológico (reclamou sempre o direito de criticar e rejeitar qualquer tradição ou autoridade, baseada na pura irracionalidade, preconceito ou na aleatoriedade. (POPPER, 2006)

$\mathrm{O}$ autor considera, diante de tudo que expôs, que a epistemologia otimista de Bacon e Descartes não pode ser verdadeira, mas, no entanto, ela pode ter sido a inspiração predominantemente de uma revolução intelectual e moral sem paralelo na história. Deu aos homens a esperança de por meio do conhecimento libertarem-se a si mesmos, pensar por si próprios e libertarem os outros da servidão e da miséria. Este é o caso de uma má ideia que inspirou boas ideias. (POPPER, 2006).

O autor também expressa o seu interesse pela epistemologia otimista de Platão e a teoria da anamnésis de Ménon, pela razão que elas trazem os germes do intelectualismo de Descartes e o germe das teorias da indução de Aristóteles e de Bacon. Segundo Popper (2006) Aristóteles e Bacon, entendiam por indução nem tanto a inferência de leis universais a partir da observação de casos particulares, como um método que é conduzido ao ponto em que se pode intuir ou perceber a essência ou a verdadeira natureza de uma coisa. Esse é o objetivo da maiêutica de Sócrates: a sua finalidade é ajudar-nos ou conduzir-nos à anamnésis, significa o poder de ver a verdadeira natureza ou a essência de uma coisa, essa natureza ou essência com que estávamos em contato antes do nascimento. A maiêutica e a indução têm, portanto, os mesmos objetivos.

$\mathrm{O}$ autor explica a teoria da indução, na qual Bacon faz uma distinção entre o método verdadeiro e método falso. Atribui ao método verdadeiro, a interpretação da natureza, para o método falso, antecipação da mente. 
Popper (2010) faz uma discussão sobre o termo interpretação e sobre a expressão anticipatio mentis. O significado de interpretar (não no sentido de traduzir) sofreu alterações ao longo do tempo, mesmo que o significado original de ler em voz alta para os que não são capazes de ler, estar atualmente perdido. No tempo de Bacon, interpretar não pressupunha alguma liberdade na interpretação, mas a forma tal qual estava inscrito, expondo-a e interpelando-a de uma única forma considerada correta. Sobre o significado de anticipatio mentis, na tradução de Bacon anticipatio significa preconceito (no sentido de julgar antecipadamente de modo desfavorável) ou superstição, pode-se ainda referir-se a essa expressão como albergar ideias ingênuas, primitivas ou supersticiosas acerca dos deuses.

De acordo com Popper (2006) os métodos são os seguintes: decifrar o livro aberto da natureza, que conduz ao conhecimento ou episteme e o preconceito da mente que que conduz à doxa, ou mera suposição, e à interpretação incorreta do livro da natureza. Esse último é rejeitado por Bacon, método da interpretação e o método de conjectura ou hipótese, o qual esse autor é defensor convicto. De acordo com Bacon para ler adequadamente e fielmente o livro da natureza é necessário expurgar das nossas mentes todas as antecipações, conjecturas, suposições ou preconceitos.

Levando tudo isso em consideração o autor sugere que a indução baconiana é basicamente igual à maiêutica de Sócrates, ou seja, é a preparação da mente, pela depuração dos preconceitos, no sentido de torna-la capaz de reconhecer a verdade manifesta ou de ler o livro aberto da natureza.

Em linhas gerais o estudo sobre o trabalho de Popper, possibilitou ampliar a visão acerca da epistemologia das ciências, e não apenas foca-la nas teorias de Educação. Além disso perceber que sempre existe, por trás de uma teoria, uma filosofia de fundo que sustenta certas concepções epistemológicas.

\section{Atividade Matemática: Componentes Formal, Algorítmico E Intuitivo}

Inicialmente antes de discutirmos acerca das componentes formal, intuitiva e algorítmicas de uma atividade matemática, é necessário situar esse tema no contexto do trabalho de Biehler et al (1994). Nesse trabalho o objetivo foi apresentar um estado da arte, da disciplina ${ }^{1}$ didática da matemática, enquanto área recente de conhecimento, voltada para os pesquisadores

\footnotetext{
${ }^{1}$ A expressão "didática da matemática" é assim utilizada em outros países, para nós aqui no Brasil tem mesmo efeito de educação matemática, salvo quando nos referimos à didática (da matemática) francesa, a qual possui teorias específicas, mas que também compõem a área de educação matemática.
} 
internacionais da área, fornecendo uma síntese e uma orientação para o domínio da pesquisa a partir das contribuições individuais de cada autor, essas relacionadas com a ideia geral de cada capítulo. No livro são apresentados temas como transposição didática, formação de professores, análise da linguagem e do discurso, tecnologias e EM. Nos deteremos em trazer as contribuições de Efraim Fischbein, nos tópicos relacionados à Psicologia da Educação Matemática.

Fichbein considera a Matemática a partir de dois pontos de vista: o primeiro é "a matemática como corpo de conhecimento formal, dedutivo e rigoroso, conforme é exposto nos livros textos de nível superior e a segunda é a Matemática como atividade humana" (BIEHLER, et al 1994, p.231).De acordo com o autor o fato de o objetivo da Matemática se estabelecer em um corpo de conhecimento estruturado e coerente, não exclui a necessidade de considera-la como um processo criativo.

Fischbein considera importante a interação de três componentes básicos da Matemática como atividade humana: o formal, o algorítmico e o intuitivo. O aspecto formal, segundo ele, se refere aos axiomas, definições, teoremas e provas que devem entrar como componentes ativos do processo de raciocino, eles devem ser aprendidos, organizados, verificados e usados ativamente pelo estudante. Ou seja, esses componentes não devem ser desprezados quando analisamos a Matemática como processo humano. (BIEHLER et al, 1994)

Sobre a componente algorítmica o autor expõe que o conhecimento dos componentes formais pelo sujeito, não são garantia de que ele será capaz de resolver problemas matemáticos. As capacidades matemáticas devem ser ativamente treinadas, armazenadas na forma de procedimentos de resolução, no entanto o autor alerta que o raciocínio matemático não pode ser reduzido a um sistema de procedimentos para resolução de problemas. Um sistema de habilidades mentais, por mais complexo que seja, permanece congelado e inativo quando tem que lidar com uma situação fora do padrão, é necessário que o aluno seja dotado de uma justificação formal dos procedimentos utilizados, pois aqueles que não têm uma justificação formal explicitas, serão esquecidos. (BIEHLER et al, 1994)

A terceira componente de um raciocínio matemático produtivo segundo o autor é a intuição "cognição intuitiva, compreensão intuitiva, solução intuitiva. Uma intuição cognitiva é um tipo de cognição que é aceita diretamente sem o sentimento de que qualquer tipo de justificação seja necessária” (BIEHLER et al, 1994, p.232).

O autor caracteriza uma intuição cognição, por um aparente auto evidência, por exemplo: "o todo é maior que qualquer uma das partes". As cognições intuitivas podem algumas vezes estar em concordância com as verdades logicamente justificadas, porém algumas 
vezes podem contradizê-las, podendo tornar-se obstáculos epistemológicos (Bachelard), durante o processo de aprendizagem.

Um bom exemplo histórico apresentado pelo autor é o conceito de infinito atual e infinito potencial: "Um processo é dito ser potencialmente infinito se supõe que ele pode ser levado a cabo sem nunca parar. Infinito atual refere-se a conjuntos infinitos de elementos considerados em sua totalidade o infinito atual é um conceito abstrato, contra intuitivo" (BIEHLER et al, 1994, p.232)

O autor quando fala de operações e modelos intuitivos e relata os equívocos que podem ocorrer por conta do relacionamento contraditório entre o formal e a restrição intuitiva. Em todos os ramos da Matemática, pode-se encontrar conceitos, afirmações e operações que são difíceis de entender. Um bom exemplo de equivoco muito difundido é exatamente a relação entre o todo e a parte nos conjuntos infinitos, quando há um conflito com a afirmação intuitiva existente no âmbito dos conjuntos finitos, de que o todo é maior que as partes. Para ilustrar basta considerar os conjuntos naturais e pares, que têm a mesma cardinalidade e um é parte do outro.

Essa contra- intuição é também demonstrada pelo autor quando fala dos algoritmos e modelos intuitivos, exemplificando com o modelo da operação de subtração, e também com os conceitos e representações intuitivas, como é o caso do conceito de conjuntos.

De acordo com o autor o modelo intuitivo manipula, de forma implícita o significado, o uso, e as propriedades do conceito formalmente estabelecido. O modelo intuitivo aparenta ser mais forte que o conceito formal. $\mathrm{O}$ aluno simplesmente esquece as propriedades formais e tende a manter em mente aqueles impostos pelo modelo.

Do ponto de vista do nível superior de raciocínio matemático podem ser encontrados muitos exemplos da complexidade de relação entre seus componentes formais, algorítmicos e intuitivos (BIEHLER et al, 1994), como é o caso da definição de limites. O autor se apoiou na definição de COURANT E ROBINS (1941,1978, p. 291-292): “A sequência $\boldsymbol{a}_{1}, \boldsymbol{a}_{2}, \boldsymbol{a}_{3}, \ldots$ tem um limite $\boldsymbol{a}$ quando $\boldsymbol{n}$ tende ao infinito se, correspondendo a qualquer número positivo $\mathcal{E}$ (lêse épsilon) não importa quão pequeno, existe um número inteiro $N$ (dependente de $\mathcal{E}$ ) tal que: $\left|a-a_{n}\right|<\varepsilon$ para todo $n>=N "$

Segundo Courant e Robins $(1941,1978)$ in BIEHLER, et al (1994), não se pode ir diretamente da representação intuitiva para a definição rigorosa, formal. A conclusão é que a definição formal inverte a ordem das ideias, contradiz a natural dinâmica representação do processo. E isso faz da definição de limite, de fato, contra intuitiva e de difícil entendimento. 
O termo tende (a sequência $\boldsymbol{a}_{1}, \boldsymbol{a}_{2}, \boldsymbol{a}_{3}, \ldots$ tem um limite $\boldsymbol{a}$ quando $\boldsymbol{n}$ tende ao infinito...”) não é um termo puramente abstrato. Continuamos a ter em mente, tacitamente, um modelo intuitivo. O termo "tende" tem um significado psicológico, não matemático e nem físico, expressa o infinito potencial que é intuitivamente aceitável. O fato é que existe uma relação conflituosa entre a definição formal e a representação intuitiva do conceito de limite, várias concepções equivocadas podem aparecer. O conceito de limite é contraditório (no sentido dialético, hegeliano) porque a nossa mente é naturalmente não adaptada à conceituação do infinito real. (BIEHLER et al, 1994).

A consequência de tudo isto são os obstáculos epistemológicos dos alunos a respeito das noções de limite e continuidade, isto é, as várias interpretações parciais que podemos encontrar nos estudantes (o limite nunca é atingido ou o limite é sempre atingido). A ideia de infinitude subjacente, quando se diz $n$ tende ao infinito, nos leva a concluir é que a infinidade real é contra intuitiva. (BIEHLER et al, 1994).

Par completar esta discussão que envolve o conceito de infinitude apresentamos alguns tópicos teóricos de matemática que se referem ao estudo da teoria dos conjuntos.

\section{Tópicos de Conjuntos: Infinitos, Finitos, Enumeráveis}

Neste item apresentamos alguns tópicos matemáticos acerca da teoria dos conjuntos. Destacamos a organização formal da Matemática por meio de definições, axiomas, teoremas e propriedades, além disso ressalta-se a existência de entes primitivos, ou seja, aqueles objetos não definidos, mas aceitos pela intuição como por exemplo: ponto, reta, plano. Nesse sentido apresentamos algumas definições e propriedades importantes na constituição da teoria dos conjuntos. Destacamos que os conceitos apresentados retratam um recorte do que concerne à teoria dos conjuntos, diante do que é abordado na disciplina Análise Matemática.

Segundo Lima (2004) um conjunto é formado de elementos e a relação básica entre esses elementos e o conjunto é a relação de pertinência. Dizemos que $x \in A$ (lê-se: x pertence a $A$ ) se x é um dos elementos do conjunto $A$, porém se $x$ não é elemento de $A$, então dizemos que x não pertence a $A$, ou seja $x \notin A$. Destacamos que conjunto é um conceito primitivo.

Para melhor compreensão da definição de conjuntos finitos e infinitos, é importante explicitar a definição de função, bem como de função bijetora, injetora e sobrejetora.

De forma geral uma função é definida a partir de uma terna $(A, B$, lei) $\operatorname{com} A, B$ conjuntos $A, B \neq \emptyset$ em que uma relação entre os conjuntos $A$ e $B$ é qualquer subconjunto de 
$A x B=\{(a, b) / a \in A$ e $b \in B\}$. Destaca-se entre as relações entre A e B uma função fé aquela que para cada elemento de A associa um único elemento de $\mathrm{B}$.

De acordo com Lima (2004) uma função $f: A \rightarrow B$ possui três partes: um conjunto A, denominado domínio da função, um conjunto $\mathrm{B}$, chamado o contradomínio da função, e uma lei que permite associar, para cada elemento $x \in A$, um único elemento $f(x) \in B$ que é a imagem da função f no ponto $x$.

A partir do conceito de função podemos dizer que a uma função fé injetora se e somente se $x_{1} \neq x_{2} \Rightarrow f\left(x_{1}\right) \neq f\left(x_{2}\right)$, ou $f\left(x_{1}\right)=f\left(x_{2}\right) \Rightarrow x_{1}=x_{2}$. Por outro lado a função é dita sobrejetora (sobrejeção): $f: A \rightarrow B$ é sobrejetora $\Leftrightarrow f(A)=B$, diremos que $\mathrm{f}$ é bijetora (bijeção) ou um a um se fé injetora e sobrejetora.

Dizemos que um conjunto $X$ é finito quando é vazio ou quando existe para algum $n \in$ $\mathbb{N}$ uma bijeção $\phi: I_{n} \rightarrow X$ ou seja, X é finito $\Leftrightarrow \exists n, \exists f: I_{n} \rightarrow A$ bijetora. ( $f$ é uma função bijetora). De acordo com Lima (2004), $I_{n}$ é a indicação do conjunto $\{1, \ldots \mathrm{n}\}$ dos números naturais de $1 \mathrm{a} \mathrm{n}$, com $n \in \mathbb{N}$.

Um conjunto $X$ é dito infinito se não é finito. Ou seja se for não vazio e se dado $n \in \mathbb{N}$ e uma função qualquer $\phi: I_{n} \rightarrow X$ tem-se que $\phi$ não é bijetora. São conjuntos infinitos: os naturais, os inteiros, os racionais, os irracionais, os reais entre outros.

Um conjunto $F_{1} \subset F$ é é parte própria de $F$ se $\exists y \in F: y \notin F_{1}$.

Um resultante importante caracteriza um conjunto finito a partir das relações com suas partes próprias. É o seguinte: Se $F$ é finito e $F_{1} \subset F$ é parte própria de $\mathrm{F}$ então $\forall f: F \rightarrow F_{1}, f$ não pode ser bijetora ou seja $\nexists$ (não existe) bijeção entre um conjunto finito e uma parte própria dele, conforme corolário enunciado em Lima (2004, p. 34).

Os conjuntos podem ser classificados em enumeráveis ou não enumeráveis. A enumerabilidade está garantida para os conjuntos finitos, ou infinitos sujeitos a determinadas condições, conforme veremos a seguir. Um conjunto X é dito enumerável quando é finito ou quando infinito se existir uma bijeção $\mathrm{F}: \mathbb{N} \rightarrow X$. e pondo-se $x_{1}=f(1), x_{2}=f(2), \ldots, x_{n}=$ $f(n), \ldots$, tem-se $X=\left\{x_{1}, x_{2}, \ldots, x_{n}, \ldots\right\}$, cada bijeção é chamada uma enumeração, dos elementos de $X$.Como exemplo de conjunto enumerável apresentamos o conjunto dos números pares $P=\{0,2,4,6, \ldots\}$ cuja bijeção $f: N \rightarrow X$ é definida por $f(x)=2 x$. Também o conjunto dos números inteiros $\mathbb{Z}$, é enumerável, e como consequência o conjunto dos números racionais $\mathbb{Q}$ é enumerável, dado que $\mathbb{Q}=\mathbb{Z} X \mathbb{Z}$.

Quando se fala em finitude ou infinitude de conjuntos, vale ressaltar a noção de cardinalidade de um conjunto. No caso dos conjuntos finitos a cardinalidade representa a 
quantidade de elementos desse conjunto. A cardinalidade do conjunto $I_{n}$, denotada por: $\left|I_{n}\right|=$ $n$. O número de elementos de $\mathrm{A}=\{1,2,3\}$ denomina-se também o cardinal de $\mathrm{A}$ e indica-se: $|A|=\operatorname{card}(A)=3$. No caso de dos conjuntos infinitos pode-se relacionar cardinais da seguinte forma: $\operatorname{card}(X)=\operatorname{card}(Y)$, se e somente se existe $f: x \rightarrow Y$ bijetora. $\operatorname{card}(X)<$ $\operatorname{card}(Y)$ se e somente se existir uma função $f: A \rightarrow B$, injetora, mas não existir uma $f: X \rightarrow$ $Y$, sobrejetora (LIMA, 2004, p.52).

Pode-se demonstrar que "para todo conjunto infinito $A$, tem-se que a card $(\mathbb{N}) \leq$ card $(B) "$, dessa forma o número cardinal de um conjunto infinito enumerável é o menor dos números cardinais dos conjuntos infinitos.

A discussão desse tema matemático é relevante quanto a abordagem do conceito de conjuntos infinito e finito, quando se faz conexões com as dificuldades de compreensão de conceitos matemáticos pelos sujeitos que aprendem, por conta do efeito da contra intuição, abordada por Fischbein.

\section{Outras Teorias}

Neste tópico finalizamos nossas discussões abordando de forma breve algumas considerações teóricas a respeito de dois temas. Jogos de quadros e registro de representação semiótica e análise do pensamento humano.

As noções de quadro e jogos de quadros foram introduzidas na Didática da Matemática francesa por Douady (1986) como instrumentos para análise de fenômenos de ensino e aprendizagem. Ela define quadro sendo

constituído de ferramentas de uma parte da matemática, de relações entre objetos, de formulações eventualmente diferentes e de imagens mentais associadas a essas ferramentas e relações. Dois quadros podem ter os mesmos objetos e ser diferentes por causa das imagens e da problemática desenvolvida (DOUADY, 1993, p.389, apud ALMOULOUD, 2007, p. 64)

De acordo com Robert et al (1999), costumamos desenvolver a ideia que as noções matemáticas, interferem frequentemente em diferentes quadros. Segundo as autoras com esse termo, indicamos um domínio de trabalho matemático no qual a noção concernente pode funcionar e ser utilizada em ligação com outras, não sendo esse domínio o único campo em que a noção pode intervir.

Almoloud (2007, p.65) traz um exemplo de problema no qual a resolução envolve diferentes quadros: “de um prisma quadrangular regular, em que aresta da base mede x e a altura 
mede 3, foi cortado um cubo de aresta x. para que valores de x o volume do novo prisma, após o corte, é maior do que 2 e menos do que 4? " De acordo com o autor na resolução dessa situação problema está envolvido os seguintes quadros: geométrico, algébrico, quadro de funções, geometria analítica e quadro numérico. A situação problema está bem de acordo com o que sugere Robert et al (1999), que defende a ideia de exercícios que possam levar a contextualizar as noções utilizando diversos quadros, seja de forma explicita ou não, mas que permitam aos alunos pensarem em introduzir essas mudanças de quadros.

O especialista pratica com frequência a mudança de quadros. Contrariamente os alunos preferem trabalhar em um único quadro, bem definido, e desejam sobretudo inserir o saber em um capítulo dado. Eles preferem conhecer as ferramentas que vão colocar em funcionamento nos exercícios e os controles, e eles têm a impressão que assim trabalham mais facilmente. (ROBERT et al ,1999, tradução Igliori, 2016)

Uma outra noção importante é a noção de registro de representação semiótica e análise do funcionamento do pensamento. Trataremos desta teoria defendida pelo psicólogo Raymond Duval, de forma bem sucinta, abordando apenas alguns pontos centrais.

Registro de representação é um sistema semiótico que tem as funções cognitivas fundamentais no funcionamento cognitivo consciente. Os códigos são diferentes dos registros, pois são funcionalmente mais limitados que os registros. Essa diferença entre registros e códigos evidencia a existência de dois níveis de funcionamento cognitivo: consciente e não consciente; salienta-se que todo conhecimento implica necessariamente na mobilização desses dois níveis. (DUVAL, 1999, apud ALMOULOUD, 2007)

Quando falamos de registros colocamos em jogo o problema da aprendizagem, é importante salientar que o sujeito não tem acesso direto aos objetos matemáticos. De acordo com Duval (2003, p. 14) “os objetos matemáticos, começando pelos números, não são objetos diretamente perceptíveis ou observáveis com a ajuda de um instrumento. $\mathrm{O}$ acesso aos números está ligado à de um sistema de representação que os permite designar”.

$\mathrm{O}$ autor afirma que além dos sistemas de numeração, existem figuras geométricas, as escritas algébricas e formais, as representações gráficas e a língua natural. A originalidade da atividade matemática, de acordo com o autor se caracteriza pela mobilização simultânea de ao menos dois registros de representação ao mesmo tempo. (DUVAL, 2003)

Para analisar a atividade matemática na perspectiva de ensino e de aprendizagem, diferente da perspectiva dos matemáticos, existem dois tipos de transformações de representações semióticas: os tratamentos e as conversões. (DUVAL, 2003) 
Os tratamentos são transformações de representações dentro de um mesmo registro, por exemplo efetuar cálculos ficando estritamente no mesmo sistema de escrita ou de representação, no caso das conversões ocorre a mudança de registro, conservando-se os mesmos objetos denotados, por exemplo passa-se de uma escrita algébrica de uma equação, para uma representação gráfica. (DUVAL, 2003)

O acesso aos objetos matemáticos passa necessariamente por representações semióticas. Segundo o autor é a articulação de registros que constitui uma condição de acesso à compreensão em Matemática, em outras palavras a compreensão em Matemática implica a capacidade de mudar de registro. Isso porque não se deve jamais confundir um objeto e sua representação. (DUVAL, 2003)

\section{Reflexões Finais}

De uma forma geral os tópicos de estudo relatados neste artigo, se articulam e se complementam dentro das categorias organizadas a partir dos aspectos gerais dos temas propostos. Refletimos que os objetivos do trabalho foram alcançados, no sentido de possibilitar aos sujeitos (estudantes da pós-graduação) construir uma visão geral sobre a área.

A partir da leitura e o posterior debate sobe cada tema proposto durante o curso de TEM os estudantes elencaram um conjunto de observações conclusivas e importantes sobre sua visão a respeito da educação matemática de suas supostas teorias. Sintetizamos essas assertivas nas seguintes conclusões:

- A educação matemática vem se constituindo como uma área interdisciplinar, ao mesmo tempo consolidando-se no meio científico;

- A educação matemática ocupa-se dos processos de ensino e aprendizagem em matemática;

- Não há uma única teoria da educação matemática, mas sim diferentes teorias oriundas da psicologia, da educação, da didática, entre outras que possibilitam estudar os fenômenos do ensino e da aprendizagem;

- A didática da matemática, especialmente a didática francesa compões de teorias, como por exemplo, a teoria das situações didáticas (TSD), a teoria antropológica do didático (TAD) entre outras;

Globalmente concluímos que a experiência com essa articulação de informações teóricas, desenvolvidas no âmago da formação do futuro pesquisador, tem relevância e contribui 
para a formação dos pós-graduandos, da compreensão de como se constitui a área de educação matemática, seus conflitos, e as suas concepções teóricas.

A metodologia de estudo, de leitura e reflexão coletiva sobre textos com diferentes abordagens teóricas, permite desenvolver uma relação, no processo de pesquisa, de fontes diversas incentivando os participantes a buscar para novas fontes teóricas, além de ampliar a visão sobre as diferentes teorias que fundamentam a pesquisa em educação matemática. Nessa perspectiva formativa, ressaltamos que neste texto, encontra-se um recorte, mas que outras referências precisam ser buscadas para um maior aprofundamento teórico, no entanto essa primeira aproximação com as discussões da área foi relevante na constituição de um conjunto de conhecimentos necessários à formação do pesquisador (a) em educação matemática no Brasil.

\section{Referências}

ALMOULOUD, S.A. Fundamentos da didática da matemática. Editora UFPR. Curitiba. 2007. BIEHLER, Rolf;. SCHOLZ, RolanD W; STRÄSSER, Rudolf; WINKELMANN, Bernard.. Didatics of Mathematics as a Scientific Discipline. Klewr Academic Publishers. London. 1994.

LIMA, E. L. Curso de análise. Vol. 1. Rio de Janeiro: Associação Instituto Nacional de matemática Pura e Aplicada, 2004.

DUVAL, R. Registros de representação semióticas e funcionamento cognitivo da compreensão em matemática. In MACHADO, S. D. A. Aprendizagem em matemática. Campinas. Papiros, 2003.

IGLIORI, S. B. C.; MIGUEL, A.; GANICA, V. M.; D’AMBROSIO, U. A Educação Matemática: breve histórico, ações implementadas e questões sobre sua disciplinarização. Revista Brasileira de Educação Matemática. n 27, 2004.

POPPER, K. Conjecturas e Refutações. Almedina. Coimbra. 2006.

ROBERT, A.; LATTUAI, M.; J. PENNINCKX, J. L'enseignement des mathematiques au lycée: Un point de vue didactique. Editora: elipses 1999.

SRIRAMAN, B e LYN E. Theories of Mathematics Education. Springer. New Yoork. 2010

ROBERT, A. ; LATTUAI, M.; PENNINCKX, J. L'enseignement des mathematiques au lycée: Un point de vue didactique. Editora: elipses 1999.

SANTOS, C. A. B. Formação de professores de matemática: contribuições de teorias didáticas no estudo das noções de área e perímetro. 2008. 156 f. Dissertação (Mestrado em Ensino de Ciências e Matemática) - Universidade Cruzeiro do Sul, São Paulo, 2008.

PONTE, J. P.; CHAPMAN, O. Mathematics teachers' knowledge and practices. In: GUTIERREZ, A.; BOERO, P. (Eds.). Handbook of research on the psychology of mathematics education: Past, present and future. Rotterdam: Sense Publisher, 2006. p. 461 - 494.

MIGUEL, A. Percursos Indisciplinares na Atividade de Pesquisa em História (da Educação 
Matemática): entre jogos discursivos como práticas e práticas como jogos discursivos. Bolema, Rio Claro, v. 23, n. 35A, abr. 2010. 